\title{
The Risk of Clostridioides difficile Infection in Cirrhotic Patients Receiving Norfloxacin for Secondary Prophylaxis of Spontaneous Bacterial Peritonitis-A Real Life Cohort
}

\author{
Irina Girleanu ${ }^{1,2}{ }^{\infty}$, Anca Trifan ${ }^{1,2, *} \oplus$, Laura Huiban ${ }^{1,2}$, Cristina Muzica ${ }^{1,2} \oplus$, Roxana Nemteanu ${ }^{1,2}$, \\ Andreea Teodorescu 1,2, Ana Maria Singeap 1,2®, Camelia Cojocariu 1,2®, Stefan Chiriac $1,2 \oplus$, Oana Petrea ${ }^{1,2}$, \\ Sebastian Zenovia ${ }^{1,2} \mathbb{D}$, Robert Nastasa ${ }^{1,2} \mathbb{D}$, Tudor Cuciureanu ${ }^{1,2} \mathbb{D}$ and Carol Stanciu ${ }^{1,2}$ \\ 1 Gastroenterology Department "Grigore T. Popa", University of Medicine and Pharmacy, \\ 700111 Iasi, Romania; gilda_iri25@yahoo.com (I.G.); huiban.laura@yahoo.com (L.H.); \\ lungu.christina@yahoo.com (C.M.); maxim_roxxana@yahoo.com (R.N.); \\ andreea.teodorescu19@yahoo.com (A.T.); anamaria.singeap@yahoo.com (A.M.S.); \\ cameliacojocariu@yahoo.com (C.C.); stefannchiriac@yahoo.com (S.C.); stoica_oanacristina@yahoo.com (O.P.); \\ sebastianzenovia20@gmail.com (S.Z.); robertnastasa948@gmail.com (R.N.); \\ drcuciureanutudor@gmail.com (T.C.); stanciucarol@yahoo.com (C.S.) \\ check for \\ updates \\ 2 Institute of Gastroenterology and Hepatology, "St. Spiridon" University Hospital, 700111 Iasi, Romania \\ * Correspondence: ancatrifan@yahoo.com; Tel.: +40-762-278-575
}

Citation: Girleanu, I.; Trifan, A.; Huiban, L.; Muzica, C.; Nemteanu, R.; Teodorescu, A.; Singeap, A.M.; Cojocariu, C.; Chiriac, S.; Petrea, O.; et al. The Risk of Clostridioides difficile Infection in Cirrhotic Patients Receiving Norfloxacin for Secondary Prophylaxis of Spontaneous Bacterial Peritonitis-A Real Life Cohort. Medicina 2021, 57, 964. https:// doi.org/10.3390/medicina57090964

Academic Editors:

Giovanni Tarantino and Adolfo Francesco Attili

Received: 26 July 2021

Accepted: 11 September 2021

Published: 13 September 2021

Publisher's Note: MDPI stays neutral with regard to jurisdictional claims in published maps and institutional affiliations.

Copyright: (c) 2021 by the authors. Licensee MDPI, Basel, Switzerland. This article is an open access article distributed under the terms and conditions of the Creative Commons Attribution (CC BY) license (https:// creativecommons.org/licenses/by/ $4.0 /)$.

\begin{abstract}
Background and Objectives: Spontaneous bacterial peritonitis (SBP) is a life-threatening complication of liver cirrhosis. Antibiotic prophylaxis is effective but can lead to an increased incidence of Clostridioides difficile infection (CDI). The aim of this study was to evaluate the incidence of CDI and the risk factors in cirrhotic patients with a previous episode of SBP receiving norfloxacin as secondary prophylaxis. Materials and Methods: We performed a prospective, cohort study including patients with liver cirrhosis and SBP, successfully treated over a 2-year period in a tertiary university hospital. All the patients received secondary prophylaxis for SBP with norfloxacin $400 \mathrm{mg} /$ day. Results: There were 122 patients with liver cirrhosis and SBP included (mean age $57.5 \pm 10.8$ years, $65.5 \%$ males). Alcoholic cirrhosis was the major etiology accounting for $63.1 \%$ of cases. The mean MELD score was $19.7 \pm 6.1$. Twenty-three (18.8\%) of all patients developed CDI during followup, corresponding to an incidence of 24.8 cases per 10,000 person-years. The multivariate Cox regression analysis demonstrated that alcoholic LC etiology (HR 1.40, 95\% CI 1.104-2.441, $p=0.029$ ) and Child-Pugh C class (HR 2.50, 95\% CI 1.257-3.850, $p=0.034$ ) were independent risk factors for CDI development during norfloxacin secondary prophylaxis. The development of CDI did not influence the mortality rates in cirrhotic patients with SBP receiving norfloxacin. Conclusions: Cirrhotic patients with SBP and Child-Pugh C class and alcoholic liver cirrhosis had a higher risk of developing Clostridioides difficile infection during norfloxacin secondary prophylaxis. In patients with alcoholic Child-Pugh C class liver cirrhosis, alternative prophylaxis should be evaluated as SBP secondary prophylaxis.
\end{abstract}

Keywords: Clostridioides difficile infection; liver cirrhosis; spontaneous bacterial peritonitis; norfloxacin

\section{Introduction}

Spontaneous bacterial peritonitis (SBP) is a severe complication of liver cirrhosis (LC) associated with high mortality [1,2]. SBP occurs in 10-30\% of adult cirrhotic patients with ascites and has an in-hospital mortality rate of $20-40 \%[1,2]$.

Norfloxacin is a quinolone with limited absorption from the gastrointestinal tract which has antibacterial activity against Gram-negative bacteria. It has been reported that norfloxacin determines gut decontamination and has high efficacy in SBP secondary prophylaxis in patients with LC $[2,3]$. 
The EASL [4] and AASLD [5] guidelines recommend that cirrhotic patients with previous episodes of SBP should receive long-term secondary prophylaxis with norfloxacin (400 mg/day) as long as they have ascites. The efficacy of this treatment was first demonstrated by Gines et al. who reported that the use of norfloxacin as secondary prophylaxis for SBP decreased the recurrence of SBP from $68 \%$ to $20 \%$ [2]. However, there are still controversies regarding the safety of long-term use of norfloxacin. Thus, the European Medicines Agency has released a warning regarding quinolone antibiotics, recommending a restriction in the use of these drugs because of possible side effects such as tendinitis, tendon rupture, hyperglycemia, and aortic aneurysm or dissection [6]. In addition, bacterial resistance should be a major concern in cirrhotic patients, as most of them have had previous hospitalizations and a high probability of being colonized by multidrug resistant bacteria. Moreover, in recent years, an alarm sign has been raised regarding the long-term safety of this treatment regarding the risk of Clostridioides difficile infection (CDI). The associated CDI may have a major impact on the outcome of cirrhosis, including higher mortality rates [7].

These data suggest that the use of quinolones for SBP secondary prophylaxis in patients with LC should be reconsidered. The aim of this study was to evaluate the incidence and the risk factors for CDI development in patients receiving long-term norfloxacin for secondary prophylaxis of SBP.

\section{Materials and Methods}

\subsection{Patients}

In this prospective observational cohort study we included all consecutive patients with liver cirrhosis who were hospitalized for SBP between January 2018 and December 2019 for SBP in a tertiary university hospital. The study was approved by the internal review board and Ethical Committee (number 1284/24 November 2017). All the patients were successfully treated for SBP. On the day of hospital discharge, all patients received the recommendation for secondary prophylaxis of SBP. The patients were followed up to a maximum of 24 months, the median follow-up period being 7 months. Follow-up was until the end of the study (December 2019), death or CDI development.

We excluded patients with hepatocellular carcinoma, those who died during hospitalization, patients receiving immunosuppressive drugs, and those with human immunodeficiency virus infection, known hypersensitivity or intolerance to norfloxacin, previous seizure, prior trans-jugular intrahepatic portosystemic shunting, prior solid organ transplantation, prior episodes of SBP, or associated illnesses with a life expectancy of 1 month or who could not be regularly followed-up. All patients were evaluated every 6 months or whenever imposed by LC complications.

Liver cirrhosis diagnosis was based on clinical, laboratory and imaging findings. The severity of liver cirrhosis was evaluated by Child-Pugh class and Model of End-Stage Liver Disease (MELD) score. Ascites was diagnosed by abdominal ultrasound. Comorbidities were recorded for all the patients. All the patients diagnosed with SBP were treated according to the recent guidelines [4,5]. At discharge the patients included in the study received norfloxacin $400 \mathrm{mg}$ /day as secondary prophylaxis of SBP according to the level of their ascites.

\subsection{Clostridioides Difficile Infection}

CDI was diagnosed based on the presence of more than three watery stools within $24 \mathrm{~h}$, plus the presence of $C$. difficile toxins A and/or B (enzyme immunoassay) in stool samples.

Community-associated CDI was defined as the onset of CDI outside a healthcare facility or within $48 \mathrm{~h}$ following admission to a healthcare facility, without contact from a healthcare facility within the previous 12 weeks $[8,9]$. 
Nosocomial CDI was defined as CDI with onset of symptoms on day three or later, following admission to hospital, or in the community within four weeks of discharge from a healthcare facility [9].

Recurrent $C D I$ was defined as diarrheal stools with a positive laboratory test more than 2 weeks after end of treatment, and less than 8 weeks following the onset of a previous episode $[8,10]$.

In all patients, an informed written consent to use their clinical data for scientific purposes was systematically obtained at entry. The study was conducted in accordance with the Declaration of Helsinki.

\subsection{Statistical Analysis}

Categorical variables were expressed as frequency and percentage. Continuous variables were expressed as mean plus/minus standard variation for normally distributed continuous data, and as median and range (25th to 75 th percentile) to describe non-normally distributed continuous data. Groups were compared using $\chi 2$ test for categorical variables, and using independent $t$ test or Mann-Whitney $U$ test for continuous variables (depending on data distribution). Univariate analysis was performed for each recorded data. Variables with $p<0.1$ in univariate analysis were included in multivariate analysis (Cox regression). Odds ratio (OR) with $95 \%$ confidence interval (CI) was calculated for qualitative variables included in the logistic regression. $p$ value $<0.05$ was considered statistically significant. All statistical analyses were performed using SPSS 20.0 software (SPSS Inc., Chicago, IL, USA).

\section{Results}

A total of 2520 patients with liver cirrhosis were admitted to our tertiary hospital during the study period, of whom $272(10.8 \%)$ were diagnosed with SBP and only 122 with first episode of SBP were eligible for the study. Most of the patients were males (65.5\%), mean age $57.5 \pm 10.8$ years and had alcoholic liver cirrhosis $(63.1 \%)$. Baseline characteristics of the patients included in the study are presented in Table 1 . The majority of the patients had large ascites (62.3\%) and hepatic encephalopathy (85.2\%).The mean MELD score was $19.7 \pm 6.1$ and Child-Pugh class $C$ patients $(69.7 \%)$ were the most prevalent.

All the patients included in the study were diagnosed with SBP, and the majority (105 patients-86.1\%) had community-acquired SBP. All the patients received secondary SBP prophylaxis with norfloxacin $400 \mathrm{mg} /$ day as long as they had ascites. Most of the patients received non-selective beta-blockers $(72.1 \%)$ and only 26 patients $(21.3 \%)$ had chronic treatment with PPIs. The median follow-up during the treatment period was 7 months.

Of all the patients included in the study, 23 patients (18.8\%) developed CDI during follow-up. The overall CDI incidence rate was 24.8 cases per 10,000 person-years. Three patients were diagnosed with healthcare-associated CDI. These were diagnosed with CDI during hospitalization for hepatic encephalopathy. Six patients (26.1\%) had recurrent form of CDI. All the patients received treatment with vancomycin $125 \mathrm{mg}$ every $6 \mathrm{~h}$ orally for 10 days. In ten patients the dose of vancomycin was increased to $250 \mathrm{mg}$ every $6 \mathrm{~h}$ as they did not response to the initial dose. Four patients with recurrent CDI received the tapering vancomycin regimen. Fidaxomicin was used in one patient that relapsed after tapering with vancomicin.

There was no significant difference in the presence of hepatic encephalopathy or hepato-renal syndrome, the concomitant use of beta-blockers (BB) or proton pump inhibitors (PPIs), as well as for most of the laboratory parameters, between cirrhotics that developed CDI and those without (Table 1$)$. The majority of the patients $(85.2 \%)$ received rifaximin for hepatic encephalopathy prophylaxis. However, the patients that developed CDI during follow-up were predominantly males ( $86.9 \%$ vs. $60.6 \%, p=0.017)$, had significantly higher Child-Pugh score (12 points vs. 10 points, $p=0.016$ ) and more frequent alcoholic etiology of LC ( $78.3 \%$ vs. $59.6 \% ; p=0.030)$. No previous reported quinolone side effects were identified in our cohort. 
Table 1. The characteristics of the study groups.

\begin{tabular}{|c|c|c|c|c|}
\hline Parameter & $\begin{array}{l}\text { All Patients } \\
\quad n=122\end{array}$ & $\begin{array}{c}\text { Patients with } \\
\text { CDI } \\
n=23\end{array}$ & $\begin{array}{l}\text { Patients without CDI } \\
\qquad N=99\end{array}$ & $p$ \\
\hline Age, years, Mean $\pm S D$ & $57.5 \pm 10.8$ & $57.8 \pm 11.8$ & $57.4 \pm 10.7$ & 0.874 \\
\hline $\begin{array}{l}\text { Mean follow-up, months, Median, } \\
\text { (IQR) }\end{array}$ & $7(2-15)$ & $7(2.5-15.5)$ & $7(2-14.5)$ & 0.638 \\
\hline Gender, male, $n(\%)$ & $80(65.5)$ & $20(86.9)$ & $60(60.6)$ & 0.017 \\
\hline Etiology of cirrhosis, $n(\%)$ & & & & 0.030 \\
\hline Alcohol & $77(63.1)$ & $18(78.3)$ & $59(59.6)$ & \\
\hline HBV & $26(21.3)$ & $5(21.7)$ & $21(21.2)$ & \\
\hline $\mathrm{HCV}$ & $19(15.6)$ & $0(0)$ & $19(19.2)$ & \\
\hline Child-Pugh class, $n(\%)$ & & & & 0.045 \\
\hline B & $37(30.3)$ & $3(13.1)$ & $34(34.3)$ & \\
\hline $\mathrm{C}$ & $85(69.7)$ & $20(86.9)$ & $65(65.7)$ & \\
\hline Child-Pugh score, Median, (IQR) & $10(9-12)$ & $12(10-12.5)$ & $10(9-12)$ & 0.016 \\
\hline MELD, Mean \pm SD & $19.7 \pm 6.1$ & $21.6 \pm 7.9$ & $19.3 \pm 5.5$ & 0.095 \\
\hline Grade 3 ascites, $n(\%)$ & $76(62.3)$ & $18(78.2)$ & $58(58.6)$ & 0.079 \\
\hline ALT, UI/L, Median, (IQR) & $33(24-65)$ & $44(31-66)$ & $32(24-63)$ & 0.290 \\
\hline Platelets $\times 10^{5}$, Median, (IQR) & $118(78-142)$ & $100(76-128)$ & $122(79-144)$ & 0.046 \\
\hline INR, Median, (IQR) & $1.62(1.4-1.95)$ & $1.9(1.47-2.36)$ & $1.6(1.38-1.9)$ & 0.059 \\
\hline $\begin{array}{c}\text { Total bilirubine, } \mathrm{mg} / \mathrm{dl}, \text { Median, } \\
\text { (IQR) }\end{array}$ & $4.2(1.79-7.72)$ & $7.28(2.18-8.44)$ & $4.06(1.79-7.08)$ & 0.203 \\
\hline Albumin g/dl, Median, (IQR) & $2.19(1.93-2.77)$ & $2.26(1.98-2.9)$ & $2.17(1.9-2.7)$ & 0.282 \\
\hline Creatinine mg/dl, Median, (IQR) & $0.79(0.64-1.22)$ & $0.81(0.76-1.53)$ & $0.77(0.63-1.18)$ & 0.211 \\
\hline CRP, g/dl, Median, (IQR) & $2.9(1.8-6.7)$ & $2.7(2.1-7.9)$ & $2.9(1.7-6.1)$ & 0.736 \\
\hline SBP recurrence, $n(\%)$ & $18(14.8)$ & $6(26.1)$ & $12(12.1)$ & 0.089 \\
\hline Death, $n(\%)$ & $66(54.1)$ & $14(60.8)$ & $52(52.5)$ & 0.496 \\
\hline PPIs, $n(\%)$ & $26(21.3)$ & $5(21.7)$ & $21(21.2)$ & 0.956 \\
\hline BBs, $n(\%)$ & $88(72.1)$ & $18(78.2)$ & $70(70.7)$ & 0.467 \\
\hline Rifaximin, $n(\%)$ & $104(85.2)$ & $20(86.9)$ & $84(84.8)$ & 0.797 \\
\hline $\begin{array}{l}\text { Number of admissions during } \\
\text { follow-up, Mean } \pm \text { SD }\end{array}$ & $2.27 \pm 1.48$ & $1.91 \pm 1.41$ & $2.36 \pm 1.50$ & 0.192 \\
\hline $\begin{array}{l}\text { Antibiotic treatment during } \\
\text { follow-up, } n(\%)\end{array}$ & $12(9.8)$ & $2(8.7)$ & $10(10.1)$ & 0.838 \\
\hline $\begin{array}{l}\text { Total proteins ascites, Median, } \\
\text { (IQR) }\end{array}$ & $1.1(0.8-1.6)$ & $1.1(0.8-1.46)$ & $1.1(0.8-1.65)$ & 0.760 \\
\hline
\end{tabular}

CDI: Clostridioides difficile infection; SD: standard deviation; IQR: interquartile range; HBV: hepatitis B virus; HCV: hepatitis C virus; MELD: Model for End-Stage Liver Disease; ALT: alanine aminotransferase; INR: International Normalized Ratio; CRP: C-reactive protein, SBP: spontaneous bacterial peritonitis; PPIs: proton pump inhibitors; BB: beta-blockers. The bold values are statistically significant.

Eighteen patients (14.8\%) had SBP recurrence during follow-up. The development of CDI infection did not influence SBP recurrence rate. During follow-up 66 patients $(54.1 \%)$ died. The mortality rate was similar in patients with or without CDI $(60.8 \%$ vs. $52.5 \%$, $p=0.496)$. During the study period the median number of admissions was also similar between the two groups $(1.91 \pm 1.41$ vs. $2.36 \pm 1.50 ; p=0.192)$. Twelve patients $(9.8 \%)$ received antibiotic treatment during follow-up, with no significant difference between the study groups $(8.7 \%$ vs. $10.1 \%$; $p=0.838)$. Seven patients received Ciprofloxacin for 
urinary tract infection, three patients received Amoxicillin for respiratory tract infection, and two patients received cefotaxime for acute cholecystitis and lobar pneumonia. None of the patients received liver transplant during the follow-up.

The results of the univariate and multivariate logistic regression analyses are shown in Table 2. The males with alcoholic LC, Child-Pugh C class and large ascites were at risk of developing CDI during follow-up. The multivariate Cox regression analysis demonstrated that alcoholic LC etiology (HR 3.18, 95\% CI 1.104-2.441, $p=0.029$ ) and Child-Pugh C class (HR 2.50, 95\% CI 1.257-3.850, $p=0.034$ ) were independent risk factors for CDI development during norfloxacin secondary prophylaxis for SBP.

Table 2. Risk factors for CDI-univariate and multivariate analyses.

\begin{tabular}{|c|c|c|c|c|c|c|}
\hline \multirow[t]{2}{*}{ Parameter } & \multicolumn{3}{|c|}{ Univariate Analysis } & \multicolumn{3}{|c|}{ Multivariate Analysis } \\
\hline & OR & $95 \% \mathrm{CI}$ & $p$-Value & HR & $95 \% \mathrm{CI}$ & $p$-Value \\
\hline Alcoholic etiology & 1.38 & 1.082-1.775 & 0.030 & 3.18 & $1.104-2.441$ & 0.029 \\
\hline Child-Pugh C class & 1.32 & $1.070-1.639$ & 0.033 & 2.50 & $1.257-3.850$ & 0.034 \\
\hline Age $>65$ years & 1.23 & $0.558-2.715$ & 0.615 & & & \\
\hline Males & 1.43 & $1.147-1.795$ & 0.011 & & & \\
\hline Grade 3 ascites & 1.33 & $1.018-1.753$ & 0.045 & & & \\
\hline Comorbidities & 0.56 & $0.273-1.153$ & 0.069 & & & \\
\hline $\begin{array}{l}\text { Ascitic liquid proteins } \\
<1.5 \mathrm{~g} / \mathrm{L}\end{array}$ & 1.01 & $0.724-1.406$ & 0.959 & & & \\
\hline Rifaximin & 1.02 & $0.857-1.226$ & 0.795 & & & \\
\hline PPIs & 1.10 & $0.862-1.421$ & 0.458 & & & \\
\hline
\end{tabular}

CDI: Clostridioides difficile infection; OR: odds ratio; CI: confidence interval; HR: hazard ratio; PPIs: proton pump inhibitors. The bold values are statistically significant.

\section{Discussion}

Previous studies have evaluated the incidence of CDI in patients with liver cirrhosis and concluded that it is higher than in the general population [7]. Patients with LC are prone to develop infection complications especially in the advanced form of this disease. Previous hospitalization, immuno-compromised system, comorbidities and most importantly previous antibiotic treatment were the main risk factors for CDI development in patients with LC. It was also demonstrated that the development of CDI in cirrhotic patients is associated with an increased risk of mortality, prolonged hospitalization and higher hospitalization costs [7].

SBP is a severe complication of LC associated with a high risk of mortality. The secondary prophylaxis with norfloxacin has proven to be effective in these patients [2]. Gut decontamination by eliminating the aerobic gram-negative bacilli reduces the rate of SBP recurrence caused by Enterobacteriaceae [11]. Norfloxacin is a quinolone with low permeability and solubility, characteristics associated with selectivity in bowel decontamination. Moreover, in vitro studies demonstrated that norfloxacin could have an anti-inflammatory effect by decreasing the level of TNF-alfa, explaining the positive effect on mortality [12-14].

Even if the efficacy of this treatment was clearly demonstrated, questions regarding its safety were raised recently. Several Food and Drug Administration Drug Safety Communications [15] preceded the European Medicines Agency alert [6]. The fluoroquinolone/quinolone use was associated with significant hypoglycemia and side effects involving the tendons, muscles, joints, and nerves with an increased risk of developing tendinitis and tendon rupture. Moreover, an increased incidence of aortic aneurysm or dissection secondary to quinolone use was demonstrated [16,17]. Considering all these side effects concerns have been raised regarding the safety of long-term administration of norfloxacin in patients with LC. The aim of our study was to evaluate the incidence and the 
risk factors associated with the CDI development in patients with $\mathrm{LC}$ receiving norfloxacin as secondary prophylaxis of SBP.

In our cohort, the incidence of CDI cirrhotic patients was 24.8 cases per 10,000 personyear, lower than the incidence reported in a cohort of cirrhotic patients with HE [18]. Previous studies demonstrated that in the general population treated with antibiotics, $5 \%$ of the patients developed CDI [19]; in our cohort $6.7 \%$ developed CDI during norfloxacin secondary SBP prophylaxis. It should be also mentioned that the majority of the studies on CDI epidemiology in LC were retrospective and use different methods of CDI diagnosis, with a high risk of underestimating the real incidence of this disease [20]. Most of the patients developed CDI infection after 6 months of norfloxacin prophylaxis and the presence of CDI did not influence mortality. The patients with alcoholic liver cirrhosis and Child-Pugh class $\mathrm{C}$ had a significant higher risk of developing CDI during follow-up. Sundaram et al. also reported a significantly higher prevalence of CDI among patients with alcoholic liver disease compared to those without alcoholic liver disease (1.62\% vs. $1.04 \%$, $p<0.001$ ) [21] and these data were confirmed by our study. The recurrence rate was only $14.8 \%$, comparable with the data previously reported [2]. It has to be mentioned that most of the patients included in our study also received rifaximin for hepatic encephalopathy prophylaxis. Even if Bajaj et al. demonstrated that cirrhotic patients with CDI have a higher mortality rate and length of hospital stay compared with those without CDI [7], in our cohort the CDI infection did not influence the mortality rate. These data are comparable with data obtained in patients with LC, but without SBP [22].

Most of the randomized controlled trials (RCT) did not report CDI as complication of long-term antibiotic prophylaxis for variceal hemorrhage [3] or SBP [11,23,24]; moreover, norfloxacin was associated with reduced Clostridium spp in patients' stools [2], although, when compared to other antibiotic classes, but not to placebo, norfloxacin was associated with CDI in $9.7 \%$ of cases compared to no cases in the co-trimoxazole group [25].

Our real-world data partially confirmed the data from RTC. In the RCT, Norfloxacin was found to reduce the probability of recurrence of SBP, as Gines et al. demonstrated [2,26], and these data were confirmed by our study, although the risk of CDI still remained in our cohort.

Our study has some strengths and also several limitations. Thus, it is the first study that had as primary outcomes the evaluation of the incidence and risk factors for developing CDI in cirrhotic patients receiving long-term norfloxacin prophylaxis for SBP. However, as a single center study it is more likely to produce bias secondary to the small number of cases or underdiagnosed CDI in some cases. In addition, the study provides no information on the $C$. difficile strain.

\section{Conclusions}

Patients with Child-Pugh class $\mathrm{C}$ alcoholic liver cirrhosis have a high risk of developing CDI during long-term norfloxacin treatment for SBP secondary prophylaxis. For these patients, alternative prophylaxis should be evaluated. SBP secondary prophylaxis should be personalized in order to outweigh the risks associated with the CDI development.

Author Contributions: All authors participated in discussion; writing and/or editing of the manuscript have made significant contribution to this manuscript. All authors accept responsibility for its content. A.T. (Anca Trifan), C.C., C.S., I.G., participated in the design of the review, collected the data, analysis and interpretation, manuscript preparation and revision, and drafted the manuscript, and approved the final version of the final draft submitted. L.H., A.T. (Andreea Teodorescu), C.S., C.M., S.C., T.C., I.G., A.M.S., R.N. (Roxana Nemteanu), S.Z., O.P. performed acquisition of data and contributed in the drafting of the manuscript. I.G., R.N. (Robert Nastasa), S.Z., O.P., C.C., A.M.S., I.G. and T.C. were involved in the acquisition of data; A.T. (Anca Trifan), C.S., C.C., C.M., L.H. and I.G. contributed to the analysis and interpretation of data. All authors have read and agreed to the published version of the manuscript.

Funding: This research received no external funding. 
Institutional Review Board Statement: The study was conducted according to the guidelines of the Declaration of Helsinki, and approved by the Ethics Committee of "Grigore T. Popa" University of Medicine and Pharmacy (number 1284, date-24 November 2017).

Informed Consent Statement: Informed consent was obtained from all subjects involved in the study including data publication acceptance.

Data Availability Statement: Data supporting reported results can be provided as request in an electronic format.

Conflicts of Interest: The authors declare no conflict of interest.

\section{References}

1. Fiore, M.; Di Franco, S.; Alfieri, A.; Passavanti, M.B.; Pace, M.C.; Kelly, M.E.; Damiani, G.; Leone, S. Spontaneous bacterial peritonitis caused by Gram-negative bacteria: An update of epidemiology and antimicrobial treatments. Expert Rev. Gastroenterol. Hepatol. 2019, 13, 683-692. [CrossRef]

2. Ginés, P.; Rimola, A.; Planas, R.; Vargas, V.; Marco, F.; Almela, M.; Forne, M.; Miranda, M.L.; Llach, J.; Salmerón, J.M.; et al. Norfloxacin prevents spontaneous bacterial peritonitis recurrence in cirrhosis: Results of a double-blind, placebo-controlled trial. Hepatology 1990, 12, 716-724. [CrossRef]

3. Fernández, J.; del Arbol, L.R.; Gómez, C.; Durandez, R.; Serradilla, R.; Guarner, C.; Planas, R.; Arroyo, V.; Navasa, M. Norfloxacin vs. Ceftriaxone in the Prophylaxis of Infections in Patients With Advanced Cirrhosis and Hemorrhage. Gastroenterology 2006, 131, 1049-1056. [CrossRef]

4. Angeli, P.; Bernardi, M.; Villanueva, C.; Francoz, C.; Mookerjee, R.P.; Trebicka, J.; Krag, A.; Laleman, W.; Gines, P. EASL Clinical Practice Guidelines for the management of patients with decompensated cirrhosis. J. Hepatol. 2018, 69, 406-460. [CrossRef] [PubMed]

5. Runyon, B.A. Introduction to the revised American Association for the Study of Liver Diseases Practice Guideline management of adult patients with ascites due to cirrhosis 2012. Hepatology 2013, 57, 1651-1653. [CrossRef] [PubMed]

6. European Medicines Agency. Disabling and Potentially Permanent Side Effects Lead to Suspension or Restrictions of Quinolone and Fluoroquinolone Antibiotics. 2019. Available online: https://www.ema.europa.eu/en/documents/referral/quinolonefluoroquinolone-article-31-referral-disabling-potentially-permanent-side-effects-lead_en.pdf (accessed on 21 March 2021).

7. Bajaj, J.S.; Ananthakrishnan, A.N.; Hafeezullah, M.; Zadvornova, Y.; Dye, A.; McGinley, E.L.; Saeian, K.; Heuman, D.; Sanyal, A.J.; Hoffmann, R.G. Clostridium difficile Is Associated with Poor Outcomes in Patients with Cirrhosis: A National and Tertiary Center Perspective. Am. J. Gastroenterol. 2010, 105, 106-113. [CrossRef] [PubMed]

8. Cohen, S.H.; Gerding, D.N.; Johnson, S.; Kelly, C.P.; Loo, V.G.; McDonald, L.C.; Pépin, J.L.; Wilcox, M.H. Clinical Practice Guidelines for Clostridium difficile Infection in Adults: 2010 Update by the Society for Healthcare Epidemiology of America (SHEA) and the Infectious Diseases Society of America (IDSA). Infect. Control. Hosp. Epidemiol. 2010, 31, 431-455. [CrossRef]

9. Rao, K.; Malani, P.N. Diagnosis and Treatment of Clostridioides (Clostridium) difficile Infection in Adults in 2020. JAMA 2020, 323, 1403. [CrossRef]

10. Mullish, B.H.; Quraishi, M.N.; Segal, J.P.; McCune, V.L.; Baxter, M.; Marsden, G.L.; Moore, D.J.; Colville, A.; Bhala, N.; Iqbal, T.H.; et al. The use of faecal microbiota transplant as treatment for recurrent or refractory Clostridium difficile infection and other potential indications: Joint British Society of Gastroenterology (BSG) and Healthcare Infection Society (HIS) guidelines. Gut 2018, 67, 1920-1941. [CrossRef]

11. Marciano, S.; Dirchwolf, M.; Diaz, J.M.; Bermudez, C.; Gutierrez-Acevedo, M.N.; Barcán, L.A.; Smud, A.; Giunta, D.; Gadano, A.C. Spontaneous bacterial peritonitis recurrence in patients with cirrhosis receiving secondary prophylaxis with norfloxacin. Eur. J. Gastroenterol. Hepatol. 2019, 31, 540-546. [CrossRef]

12. Dalhoff, A. Immunomodulatory Activities of Fluoroquinolones. Infection 2005, 33, 55-70. [CrossRef]

13. Gómez-Hurtado, I.; Zapater, P.; Bellot, P.; Pascual, S.; Pérez-Mateo, M.; Such, J.; Francés, R. Interleukin-10-mediated heme oxygenase 1-induced underlying mechanism in inflammatory down-regulation by norfloxacin in cirrhosis. Hepatology 2011, 53, 935-944. [CrossRef]

14. Juanola, O.; Gómez-Hurtado, I.; Zapater, P.; Moratalla, A.; Caparrós, E.; Piñero, P.; González-Navajas, J.M.; Giménez, P.; Such, J.; Francés, R. Selective intestinal decontamination with norfloxacin enhances a regulatory T cell-mediated inflammatory control mechanism in cirrhosis. Liver Int. 2016, 36, 1811-1820. [CrossRef]

15. U.S. Food and Drug. FDA in Brief: FDA Warns That Fluoroquinolone Antibiotics Can Cause Aortic Aneurysm in Certain Patients. 2018. Available online: https:/ / www.fda.gov/news-events/fda-brief/fda-brief-fda-warns-fluoroquinolone-antibiotics-cancause-aortic-aneurysm-certain-patients (accessed on 2 April 2021).

16. Lee, C.-C.; Lee, M.G.; Chen, Y.-S.; Lee, S.-H.; Chen, Y.-S.; Chen, S.-C.; Chang, S.-C. Risk of Aortic Dissection and Aortic Aneurysm in Patients Taking Oral Fluoroquinolone. JAMA Intern. Med. 2015, 175, 1839. [CrossRef]

17. Pasternak, B.; Inghammar, M.; Svanström, H. Fluoroquinolone use and risk of aortic aneurysm and dissection: Nationwide cohort study. BMJ 2018, 360, k678. [CrossRef] 
18. Stoica, O.C.; Stanciu, C.; Cojocariu, C.; Miftode, E.; Boiculese, L.; Trifan, A.; Girleanu, I. Clostridium difficile Infection in Hospitalized Cirrhotic Patients with Hepatic Encephalopathy. J. Gastrointest. Liver Dis. 2015, 24, 423-428. [CrossRef] [PubMed]

19. Borzio, M.; Salerno, F.; Piantoni, L.; Cazzaniga, M.; Angeli, P.; Bissoli, F.; Boccia, S.; Colloredo-Mels, G.; Corigliano, P.; Fornaciari, G.; et al. Bacterial infection in patients with advanced cirrhosis: A multicentre prospective study. Dig. Liver Dis. 2001, 33, 41-48. [CrossRef]

20. Trifan, A.; Stoica, O.; Stanciu, C.; Cojocariu, C.; Singeap, A.-M.; Girleanu, I.; Miftode, E. Clostridium difficile infection in patients with liver disease: A review. Eur. J. Clin. Microbiol. Infect. Dis. 2015, 34, 2313-2324. [CrossRef] [PubMed]

21. Sundaram, V.; May, F.P.; Manne, V.; Saab, S. Effects of Clostridium difficile Infection in Patients with Alcoholic Hepatitis. Clin. Gastroenterol. Hepatol. 2014, 12, 1745-1752.e2. [CrossRef] [PubMed]

22. Yan, D.; Huang, Y.-D.; Chen, Y.-B.; Lv, T.; Gu, S.-L.; Li, Y.-T.; Huang, J.-R.; Li, L.-J. Risk factors for Clostridium difficile infection in cirrhotic patients. Hepatobiliary Pancreat. Dis. Int. 2019, 18, 237-241. [CrossRef]

23. Kemp, W.; Colman, J.; Thompson, K.; Madan, A.; Vincent, M.; Chin-Dusting, J.; Kompa, A.; Krum, H.; Roberts, S. Norfloxacin treatment for clinically significant portal hypertension: Results of a randomised double-blind placebo-controlled crossover trial. Liver Int. 2009, 29, 427-433. [CrossRef] [PubMed]

24. Lontos, S.; Shelton, E.; Angus, P.W.; Vaughan, R.; Roberts, S.K.; Gordon, A.; Gow, P.J. A randomized controlled study of trimethoprim-sulfamethoxazole versus norfloxacin for the prevention of infection in cirrhotic patients: Prevention of infection in cirrhotics. J. Dig. Dis. 2014, 15, 260-267. [CrossRef] [PubMed]

25. Jafferbhoy, H.; Miller, M.H.; Shekar, C.; Lockhart, M.; Dillon, J.F. Spontaneous bacterial peritonitis prophylaxis: Reducing the incidence of $C$. difficile infection. Gut 2011, 60, A4. [CrossRef]

26. Moreau, R.; Elkrief, L.; Bureau, C.; Perarnau, J.-M.; Thévenot, T.; Saliba, F.; Louvet, A.; Nahon, P.; Lannes, A.; Anty, R.; et al. Effects of Long-term Norfloxacin Therapy in Patients With Advanced Cirrhosis. Gastroenterology 2018, 155, 1816-1827.e9. [CrossRef] [PubMed] 